\title{
OPTIMAL DISINFECTION TIMES FOR SEEDS OF MEDITERRANEAN ORCHIDS PROPAGATED ON NUTRIENT MEDIA
}

\section{EIRINI KATSALIROU ${ }^{1}$, ARGYRIOS GERAKIS ${ }^{2, *}$, XENOPHON HALDAS ${ }^{3}$, and GWENAËLLE DECONNINCK ${ }^{4}$}

\author{
${ }^{1}$ Technological Educational Institute of Ionian Islands, 28100 Argostoli, Greece \\ 2 P.O. Box 66, 28100 Argostoli, Greece \\ 318 Tsilimidou St., 28100 Argostoli, Greece \\ 47 rue des Fossés, 59800 Lille, France \\ *Corresponding author: gerakis@teiion.gr
}

\section{ABSTRACT}

\begin{abstract}
A time-consuming yet mandatory step during in vitro sexual propagation of orchids is the treatment of seeds with a disinfecting solution that also serves to scarify the seeds. If the seeds are not properly disinfected, microorganisms grow within the culture vessel, thus reducing the efficacy of the process and burdening the operation with unnecessary materials and labour. On the other hand, a long period of disinfection may damage the seed. The literature is inconclusive with respect to the proper combination of solution strength and duration of the treatment, especially with respect to Mediterranean orchids. The objective of this research is to determine optimal disinfection/scarification times for two species with thin and thick seed coats, respectively. Seeds of Anacamptis laxiflora (Lam.) and Himantoglossum robertianum (Loisel.) were treated in 1\% $\mathrm{NaClO}$ solution for 5, 15, 25, 35 and 45 minutes and sown in modified organic Malmgren medium. Logistic regression models were fitted to the results. Due to the small number of observations per treatment, regression models of infection rates on treatment duration had no more predictive ability than the mean infection rate. On the other hand, regression models of germination rates on treatment duration proved statistically significant or nearly so. Treatment of only a few minutes in $1 \% \mathrm{NaClO}$ seems to be optimal for seeds with relatively permeable seed coats such as those of A. laxiflora (Lam.). Conversely, treatment of 45 minutes in $1 \% \mathrm{NaClO}$ may be inadequate for seeds with relatively impermeable seed coats such as those of $H$. robertianum (Loisel.).
\end{abstract}

Keywords: Anacamptis laxiflora (Lam.), Cephalonia, Himantoglossum robertianum (Loisel.), in vitro propagation, Orchidaceae, scarification

\section{Introduction}

Greece hosts more than 200 species and subspecies of terrestrial orchids (Petrou et al.2011). This remarkablebiodiversity is threatened by diverse environmental pressures such as overgrazing, cultivation, urbanization, tourism, illicit collection and climate change. Meanwhile, the horticultural, nutritional and medicinal value of native orchids remains relatively unexploited. In vitro propagation of native orchids would yield multiple benefits: protection and conservation of valuable genetic resources, the development of an innovative floricultural product for export, manufacture of salep and the possibility of restoring disturbed ecosystems. It is desirable to propose a protocol for in vitro propagation suitable for Greek native orchids that can be adopted by plant propagation laboratories and professionals for the mass production of seedlings for use in restoration programs.

A time-consuming yet vital step during the in vitro sexual propagation of orchids is the treatment of seeds with a disinfecting solution. This treatment serves a dual purpose: First, to disinfect the seed. Second, to break embryo dormancy and initiate germination, a process known as chemical scarification (Rasmussen 1995). If seeds are not properly disinfected, within a few days' moulds, yeasts and (less frequently) bacteria grow within the culture vessel, reducing the efficacy of the process and thus burdening the operation with extra materials and labour. Too short a treatment may result in unduly high infection rates; too long a treatment may damage the embryo. The decision of how long to disinfect seeds is further complicated by the fact that different species have seed coats (testas) of different thickness, necessitating different treatment times. If Mediterranean orchid propagation is ever attempted at a mass scale for commercial or conservation purposes, optimal treatment times must be determined.

The literature is contradictory as to the recommended duration of disinfection/scarification. Svante Malmgren, a veteran practitioner who has propagated more than 200 terrestrial species of orchids and hybrids in vitro, recommends soaking the seeds in $0.3-1 \% \mathrm{NaClO}$ solution for 5-45 minutes (Malmgren and Nyström 2017). According to Malmgren, the appropriate combination of solution concentration and treatment duration must be determined for each species. In principle, the calibration method is straightforward: A suspension of seeds in $\mathrm{NaClO}$ solution is observed under magnification, until most seeds are bleached. Despite the simplicity of the technique, the cut-off point is subjective. In our experience, the maturity of the seed affects the outcome; we have determined the cut-off times for seeds at different stages of maturation. Overall, we found it difficult to replicate Malmgren's technique consistently.

At the other end of the spectrum is Rasmussen (1995). In the general section of his monograph, he suggests a stronger $\mathrm{NaClO}$ solution (5\%) and much longer treatment times, up to several hours. In the special section 
of his monograph, Rasmussen details the requirements for in vitro propagation of several N. European and N. American species. For the related genera Orchis/Anacamptis/Aceras he recommends treatment durations several times longer than those proposed by Malmgren. Another example is Ophrys sphegodes Mill., a species with a wide European distribution: Rasmussen proposes a treatment of 45 minutes in $0.3 \% \mathrm{NaClO}$, whereas Malmgren proposes only 4-8 minutes in a similar concentration of $\mathrm{Na}$ $\mathrm{ClO}$. For O. sphegodes, Rasmussen reports germination times of up to seven months, whereas Malmgren reports germination times of at most four weeks. Overall, Rasmussen considers Ophrys as one of the most difficult genera to germinate, whereas Malmgren considers Ophrys as one of the easiest.

These contradictions mean one of two things: First, Rassmussen consulted only a limited body of research that was available at the time. We have already questioned his broad assertion that orchids grow on poor soils (Katsalirou et al. 2016). Second, results from different experiments are not comparable; unreported factors related to laboratory materials, technique, or seed maturity confound the effects of treatment duration and concentration of the disinfecting solution. For instance, the number of seeds treated relative to the volume of solution is rarely reported in the literature, although generally a surplus of disinfectant is assumed (Rasmussen 1995). Researchers may not report certain factors if they consider them self-evident or if they do not comprehend their significance. Propagation of Mediterranean orchids in particular is poorly documented. There are just a few reports from Greece, although Greece is the richest country in Europe based on the number of taxa per unit area. The few reports that exist lack detail about the laboratory technique used (e.g., Kitsaki et al. 2004).

To identify possible factors that affect infection rates of culture vessels, we sowed 30 batches consisting of $24 \mathrm{cul}$ ture vessels each, using mature and immature seed from 27 taxa (species and subspecies) collected in Cephalonia, Greece, plus seeds of five European taxa from the collection of Svante Malmgren. Factors such as size, geometry and material in the culture vessels varied inadvertently; we had to use a variety of culture vessels due to shortage of laboratory supplies. Nevertheless, we arrived at some tentative conclusions:

a) Treatment in $0.5-1 \% \mathrm{NaClO}$ solution for less than 20 minutes for mature seed and less than 45 minutes for immature capsules may not provide adequate disinfection.

b) Immature capsules are more difficult to disinfect than mature seeds.

c) Mature seed must be free of foreign matter such as capsule fragments.

d) Operator speed counts.

The second conclusion is surprising, given that the inside of immature capsules is considered sterile. Possibly, the disinfection protocol that we followed (Koirala et al.
2013) is better suited for tropical than temperate orchids. Also, capsules of tropical orchids are robust enough to withstand blazing, but not necessarily suitable for the delicate capsules of temperate orchids.

Having acquired general experience of in vitro culture of Mediterranean orchids, we initiated a formal experiment to determine optimal seed disinfection times. The objective was to determine treatment times that minimize infection of culture vessels and maximize seed germination without unduly delaying the in vitro procedure.

\section{Materials and Methods}

\section{Preparation of disinfecting solution}

As a stock solution we used a commercial formulation of household bleach (Klinex , Unilever) with a nominal $\mathrm{NaClO}$ concentration of $4.8 \% \mathrm{w} / \mathrm{w}$. To verify the strength of the commercial formulation, we titrated three different volumes (5, 10 and $20 \mathrm{ml}$ ) with $\mathrm{AgNO}_{3}$ solution following Mohr's method (Harris 2010). The manufacturer's reported concentration was found to be accurate. The stock solution was diluted with deionised water to a final concentration of $1 \% \mathrm{w} / \mathrm{w}$. Four drops of washing up detergent per litre were added to reduce surface tension.

\section{Experimental treatments}

We opted to use mature seed for ease of storage and handling, as opposed to seed from immature capsules that must be sown shortly after collection. Combinations of five treatment durations $(5,15,25,35$ and 45 minutes) and two orchid species were tested. We decided against longer treatment times or stronger disinfecting solutions because of the effect such treatments might have on seed viability; Dowling and Jusaitis (2012) report some embryo damage after 1 or 2 hours of soaking in $5 \% \mathrm{NaClO}$. The two species of orchids were selected based on the permeability of their seed coats; based on preliminary tests, we opted for a species with a relatively permeable seed coat, Anacamptis laxiflora (Lam.), and a species with a relatively impermeable seed coat, Himantoglossum robertianum (Loisel.).

In a proper factorial experiment, combinations of treatments are assigned to culture vessels at random. However, this means we would have to keep track of five different treatment durations during each experimental run, unduly increasing the complication of the experimental setup and the possibility of operator error. Instead, we tested one treatment duration per experimental run, in reverse order; the longest duration was tested first to minimize the effect of operator learning. If we proceeded from the shortest duration to the longest, we would give undue credit to the longest duration as a result of the operator improving his or her technique. Although operator experience can be an important factor in specialized work, such as in vitro propagation, this factor should best be tested in a separate experiment. 
Each experimental run consisted of eight replicates for each species plus eight "blanks," i.e., culture vessels without seed. The blanks were subject to the same treatment as the vessels with seed, including simulated sowing on a nutrient medium. The blanks would reveal possible shortcomings in our laboratory technique that are not due to seed-borne contaminants.

\section{Field method}

The seeds were collected on the island of Cephalonia, Greece. At flowering, healthy and robust individuals of Himantoglossum robertianum (Loisel.) and Anacamptis laxiflora (Lam.) were identified in the field, photographed, labelled and recorded. At senescence, seed was collected from mature capsules. Both species are abundant enough so that seed collection did not jeopardise the natural populations. The seed was sieved to remove foreign matter such as capsule fragments, dried in a desiccator with silica gel, sealed in glass vials and stored at $-20{ }^{\circ} \mathrm{C}$ until sowing.

\section{Laboratory method}

In nature, germinating orchid seeds develop an association with symbiotic fungi that supply them with nutrients, including C. The seeds have almost no nutrient reserves of their own, so that effective germination depends on a fungus-orchid association called mycorrhiza (Garbaye 2013). It is possible to reproduce the mycorrhizal association in the laboratory. Although this approach most closely mimic nature, it is complicated because the operator must manage two organisms instead of one. Instead, many practitioners opt for a sterile nutrient solution that supplies the seed with the nutrients needed for germination and early development.

\section{Preparation of nutrient medium}

There exist numerous recipes for nutrient media for propagating terrestrial orchids (Rasmussen 1995). A few base ingredients are shared by most recipes, which makes sense, as most terrestrial plants require the same $16 \mathrm{nu}$ trients for growth and development (Marschner 1995). Some recipes add elements such as $\mathrm{Al}$ and I whose benefit in plant nutrition has not been unequivocally demonstrated; others add tropical fruit juices or tree sap, whose role has yet to be explained. We opted for a modified version of "SM-organic" (Rasmussen 1995), a time-tested formula of the veteran practitioner Svante Malmgren. The medium is termed "organic" on account of its $\mathrm{N}$ source, an amino acid mixture sold under the trade name Vaminolac ${ }^{\oplus}$. However, in Greece Vaminolac ${ }^{\oplus}$ is considered a medicine and as such cannot be sold without prescription. Therefore, we substituted Amina-Fe (Humofert), a liquid fertilizer containing amino acids and chelate Fe. Because the addition of Amina-Fe more than covers the Fe requirement in Malmgren's recipe, we omitted the Fe salt in the original formula. Further, we substituted $\mathrm{CaHPO}_{4}$ for $\mathrm{Ca}_{3}\left(\mathrm{PO}_{4}\right)_{2}$. Bottled water was substituted for tap water, on account of the high salinity of the municipal water supply (electrical conductivity at $25^{\circ} \mathrm{C}>1 \mathrm{mS} \mathrm{cm}^{-1}$ ). The formula is in Table 1.

Table 1 Formula for modified "SM-organic" nutrient medium.

\begin{tabular}{|l|c|}
\hline Ingredient & Quantity \\
\hline Bottled water to make & $1 \mathrm{I}$ \\
\hline $\mathrm{CaHPO}_{4}$ & $99 \mathrm{mg}$ \\
\hline $\mathrm{KH}_{2} \mathrm{PO}_{4}$ & $75 \mathrm{mg}$ \\
\hline $\mathrm{MgSO}_{4}-7 \mathrm{H}_{2} \mathrm{O}$ & $75 \mathrm{mg}$ \\
\hline Soluvit (water soluble vitamins) & $10 \mathrm{ml}$ \\
\hline Amina-Fe & $0.92 \mathrm{ml}$ \\
\hline Kinetin & $5 \mathrm{mg}$ \\
\hline Saccharose (sucrose) & $10 \mathrm{~g}$ \\
\hline Activated charcoal, powdered & $1 \mathrm{~g}$ \\
\hline Agar & $8 \mathrm{~g}$ \\
\hline Pineapple (Ananas comosus) juice & $25 \mathrm{ml}$ \\
\hline NH & or HCl for pH adjustment \\
\hline Potato (Solanum tuberosum) tuber & $1-2 \mathrm{drops}$ \\
\hline
\end{tabular}

a Equivalent to $75 \mathrm{mg} \mathrm{Ca}_{3}\left(\mathrm{PO}_{4}\right)_{2}$ in the original formula.

b Equivalent to $0.5 \mathrm{ml} \mathrm{Vaminolac}{ }^{\circledR}$ plus $10 \mathrm{mg} \mathrm{FeSO}_{4}$ in the original formula.

The ingredients were mixed in a 11 Erlenmeyer flask placed on a hot plate with a magnetic stirrer. After the solution cooled to ambient temperature, $\mathrm{pH}$ was adjusted to 5.5-6.0 with either $\mathrm{NH}_{3}$ or $\mathrm{HCl}$.

\section{Preparation of materials}

The nutrient medium was distributed to $250 \mathrm{ml} \mathrm{Er}$ lenmeyer flasks for autoclaving. Glassware, steel tools, filter paper, potato cubes and deionised water were also sterilized in an autoclave, a Tuttnauer 2340 programmed on a 30 minute cycle (for cold departure) or a 25 minute cycle (for hot departure) at a temperature of $121^{\circ} \mathrm{C}$ and pressure of 1.2 bar.

The sowings were done inside an Esco EQU/04-EBC2A laminar flow cabinet. The interior surfaces were wiped with cotton soaked in $70 \%$ ethanol. The culture vessels were $100 \mathrm{~mL}$ urine samplers made of polypropylene, individually wrapped in sterile packaging. All non-autoclavable materials were placed in the laminar flow cabinet and exposed to a germicidal UV lamp for 50 minutes. The workspace outside the laminar flow cabinet was also disinfected with a germicidal UV lamp for 50 minutes. The airflow in the cabinet was turned on for 15 minutes to purge airborne contaminants as per manufacturer's instructions ${ }^{1}$. The sterile seal of the culture vessels was broken. The Erlenmeyer flasks with the nutrient medium were transferred from the autoclave onto a hotplate inside the laminar flow cabinet with the thermostat set to $50^{\circ} \mathrm{C}$.

1 Esco ${ }^{\circ}$. Class II Type A/B3 Biohazard Safety Cabinets. User Operation Manual. 


\section{Seed disinfection}

The seed was disinfected in plastic test tubes sealed with a cap. Thirty mg of seed was scooped up with a spatula and placed in each tube, except those assigned as blanks. The test tubes were filled nearly to the top with disinfecting solution, capped, and shaken vigorously to remove any air bubbles in contact with the seed. The shaking was repeated every 15 minutes thereafter till the end of the disinfection period.

At the end of the disinfection period, the suspensions were decanted into Erlenmeyer flasks fitted with a polypropylene funnel lined with filter paper to recover the seed. The filter paper was soaked in the same disinfecting solution as the seed. After filtering the suspensions, each filter paper was rinsed five times with approximately $7 \mathrm{ml}$ of sterile deionised water.

\section{Sowing}

Each culture vessel was filled with approximately $17 \mathrm{ml}$ of sterile nutrient medium and a potato cube. Once the nutrient medium cooled down to about $35{ }^{\circ} \mathrm{C}$, the seeds were scraped with a spatula from the filter paper and distributed in the culture vessels. The tips of the steel tools were heat sterilized between sowing.

The culture vessels were incubated in a dark cabinet at an ambient temperature of $28^{\circ} \mathrm{C}$. At 41 days after sowing, the vessels were visually examined for the development of fungus, yeast and bacterial colonies. The infected vessels were counted and the non-infected vessels were returned to the cabinet. At 189 days after sowing, vessels with germinated seed were counted.

\section{Statistical methods}

Because the response variables are nominal (infected vs. non-infected, germinated vs. non-germinated), one way to analyse the responses is to use logistic regressions (SAS Institute 2003). The level of significance for statistical tests was set $a$ priori at $\alpha=0.05$.

\section{Results and Discussion}

The infection rate for the 40 "blank" vessels was nil, which proves that our technique is valid and that all contamination comes from the seed. The infection rates for the two species are compared in Fig. 1. Logistic regression models for both species were not statistically significant, probably owing to the small number of observations per treatment $(n=8)$. In other words, the models did not have a better predictive ability than the mean infection rate, $7.5 \%$ for A. laxiflora (Lam.) and 25\% for H. robertianum (Loisel.).

At 189 days after sowing, the seed in several of the vessels had germinated (Fig. 2). The germination rate for the 40 "blank" vessels was nil. Germination rates for the two species are compared in Fig. 3. Despite the small number of observations per treatment $(n=8)$ the logistic regression model for A. laxiflora (Lam.) was significant, and the logistic regression model for $H$. robertianum (Loisel.) nearly significant $(p=0.06)$. Model results are presented in Table 2.

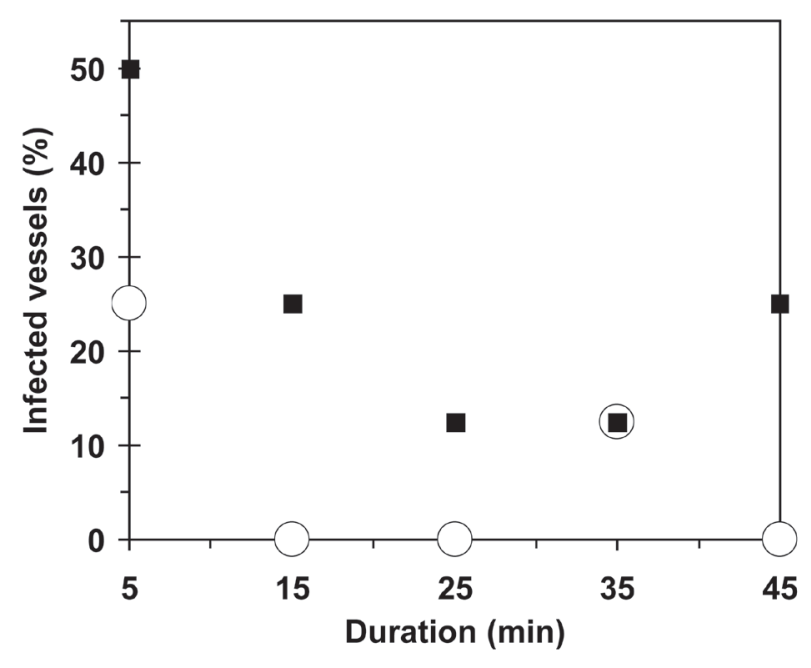

A. laxiflora $\square$ H. robertianum

Fig. 1 Effect of treatment duration on infection rates of culture vessels sown with either Anacamptis laxiflora (Lam.) or Himantoglossum robertianum (Loisel.), 41 days after sowing $(n=8)$.
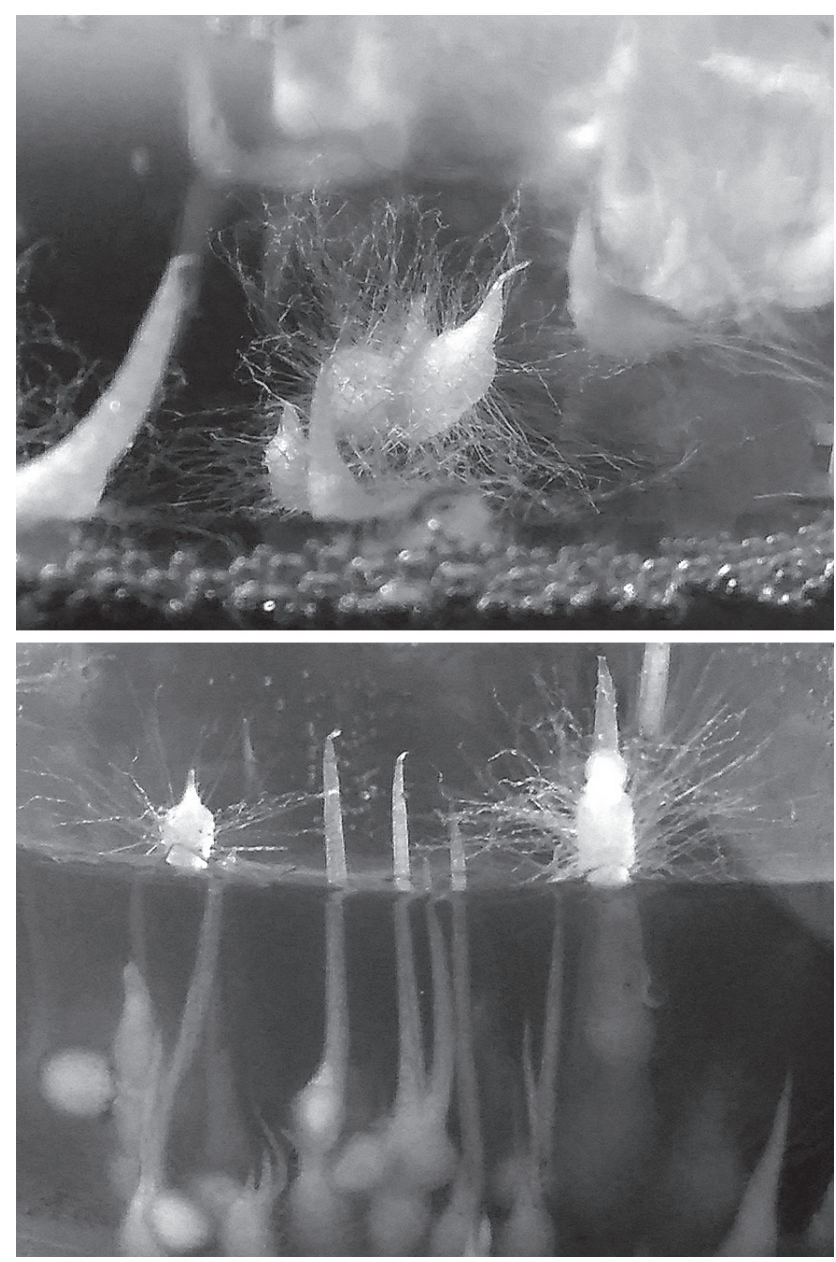

Fig. 2 Photographs of germinated seed: (a) Anacamptis laxiflora (Lam.) and (b) Himantoglossum robertianum (Loisel.). 
Table 2 Model test and parameter estimates for logistic regression of germination rates on treatment duration: $L L=\log$ likelihood, $D F=$ degrees of freedom, $\mathrm{X}^{2}=$ chi-square, $p=$ probability, $R^{2}=$ ratio of "Difference" to "Reduced" $\mathrm{LL}$.

\begin{tabular}{|c|c|c|c|c|c|c|c|c|}
\hline \multicolumn{9}{|c|}{ Whole Model Test } \\
\hline & \multicolumn{4}{|c|}{ Anacamptis laxiflora (Lam.) } & \multicolumn{4}{|c|}{ Himantoglossum robertianum (Loisel.) } \\
\hline Model & $-\mathrm{LL}$ & DF & $x^{2}$ & $p>x^{2}$ & $-\mathrm{LL}$ & DF & $x^{2}$ & $p>x^{2}$ \\
\hline Difference & 4.88 & 1 & 9.77 & 0.002 & 1.75 & 1 & 3.51 & 0.061 \\
\hline Full & 21.58 & & & & 24.71 & & & \\
\hline Reduced & 26.46 & & & & 26.46 & & & \\
\hline$R^{2}$ & 0.18 & & & & 0.07 & & & \\
\hline Observations & 40 & & & & 40 & & & \\
\hline \multicolumn{9}{|c|}{ Parameter Estimates for Log Odds of P(germinated)/P(non-germinated) } \\
\hline Term & Estimate & SE & $x^{2}$ & $p>X^{2}$ & Estimate & SE & $x^{2}$ & $p>x^{2}$ \\
\hline Intercept & 1.3827 & 0.74 & 3.51 & 0.061 & -0.5680 & 0.67 & 0.72 & 0.395 \\
\hline Duration & -0.0821 & 0.03 & 7.56 & 0.006 & 0.0452 & 0.03 & 3.22 & 0.073 \\
\hline
\end{tabular}
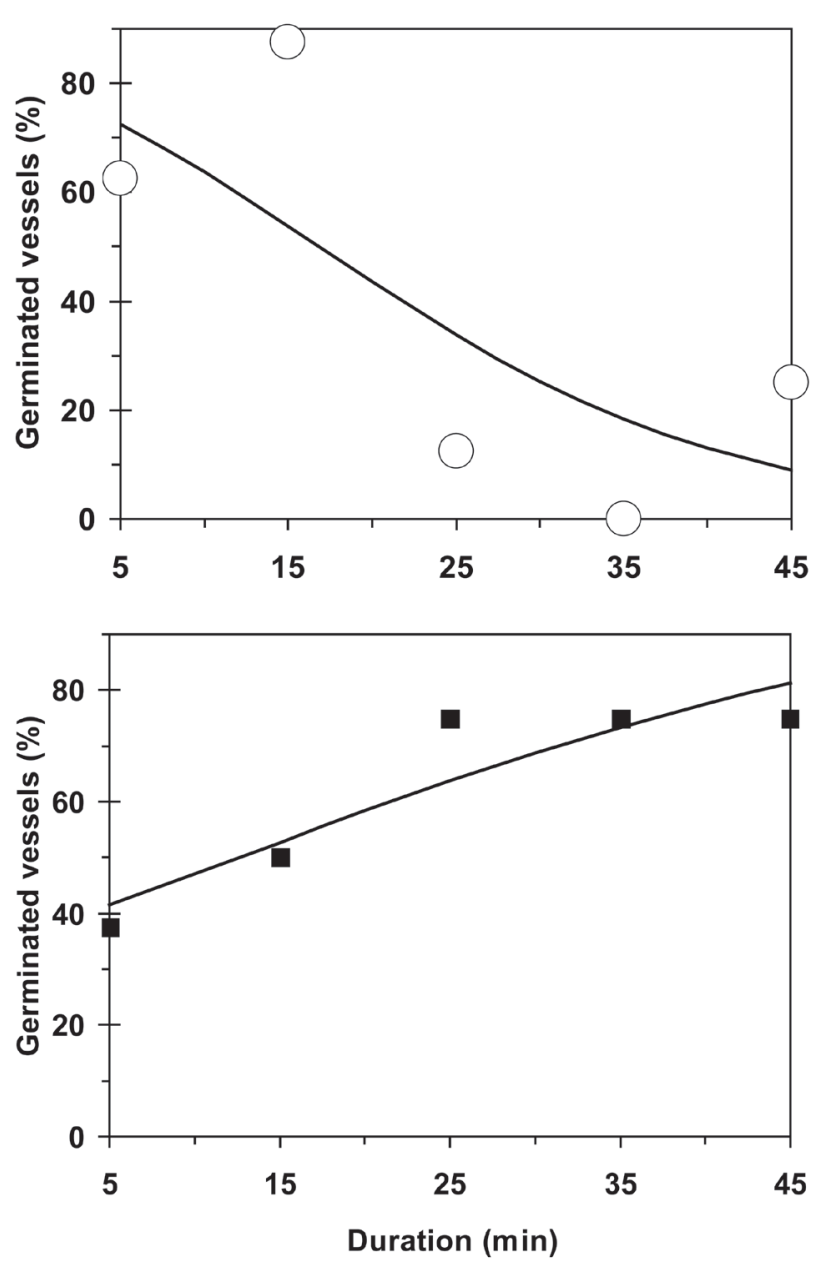

Fig. 3 Effect of treatment duration on germination rates of (a) Anacamptis laxiflora (Lam.) and (b) Himantoglossum robertianum (Loisel.), 189 days after sowing. Markers are measured points $(n=8)$ and lines fitted models.

At the end of the day what matters most is germination rates rather than infection rates, because germination rates determine how many useful seedlings are produced. In that sense, the regression models are useful for illustrating the difference in disinfection times required for germination between various species. The germina- tion rate of a species with a thin testa, such as A. laxiflora (Lam.), decline with disinfection time, whereas the germination rate of a species with a thick testa, such as H. robertianum (Loisel.), increase with disinfection time, within the range of times tested, 5 to 45 minutes. It is important that models are not extrapolated outside the interval of the times tested in order to avoid illogical predictions such as negative times.

\section{Conclusions}

Chemical scarification of orchid seeds can be a critical cost in the mass production of orchid seedlings. On one hand, too short a disinfection time may increase infection rates, which translates into a waste of labour and material resources. On the other hand, unduly long disinfection times slow down the procedure and may decrease seed viability. At the end of the day what matters most is to be able to predict germination rates, because these determine how many useful seedlings are produced. Scarification times of only a few minutes in $1 \% \mathrm{NaClO}$ seem optimal for germination of seeds with relatively permeable seed coats such as those of Anacamptis laxiflora (Lam.). Conversely, scarification times of as long as 45 minutes in $1 \% \mathrm{NaClO}$ may not be long enough for seeds with relatively impermeable seed coats such as those of Himantoglossum robertianum (Loisel.). Of course, there is a practical lower limit to the duration of the treatment, which is the time it takes to fill up, agitate and empty the test tubes containing the disinfectant solution. It follows that, for seeds with relatively permeable walls, a weaker $\mathrm{NaClO}$ solution such as $0.5 \% \mathrm{w} / \mathrm{w}$ will enable a more precise control of disinfection times.

\section{Acknowledgements}

We are indebted to Svante Malmgren and Sotiria Milla for technical advice; Elodie Garçon for assistance with in vitro propagation; and, the Technological Educational 
Institute of Ionian Islands for generous loans of facilities and equipment.

\section{REFERENCES}

Dowling N, Jusaitis M (2012) Asymbiotic in vitro germination and seed quality assessment of Australian terrestrial orchids. Aust J Bot 60: 592-601.

Garbaye J (2013) La symbiose mycorhizienne: une association entre les plantes et les champignons. Editions Quae, Versailles.

Harris DC (2010) Quantitative chemical analysis. 8th ed. W. H. Freeman, San Francisco, CA.

Katsalirou E, Gerakis A, Haldas X (2016) Soil preferences of Mediterranean orchids. J Eur Orch 48: 245-282.

Kitsaki CK, Zygouraki S, Ziobora M, Kintzios S (2004) In vitro germination, protocorm formation and plantlet development of mature versus immature seeds from several Ophrys species (Orchidaceae). Plant Cell Rep 23: 284-290.

Koirala D, Pradhan S, Pant B (2013) Asymbiotic seed germination and plantlet development of Coelogyne fuscescens Lindl., a medicinal orchid of Nepal. Sci World 11: 97-100.

Malmgren S, Nyström H (2017) Orchid propagation. http://www lidaforsgardencom/Orchids/engelskhtm. Accessed30May2017. Marschner H (1995) Mineral nutrition of higher plants. Academic Press, San Diego, CA.

Petrou N, Petrou M, Giannakoulias M (2011) Orchids of Greece. Koan/Eight Clouds, Athens.

Rasmussen HN (1995) Terrestrial orchids: From seed to mycotrophic plant. Cambridge U. Press, Cambridge.

SAS Institute (2003) JMP statistics and graphics guide. Version 5.1.2. SAS Institute, Cary, NC. 